\title{
Personality and Values Based Materialism: Their Relationship and Origins
}

\author{
Aaron C. Ahuvia \\ Department of Marketing \\ University of Michigan-Dearborn \\ Nancy Y. Wong \\ Department of Marketing \\ Georgia Tech University, DuPree College of Management
}

\begin{abstract}
This research investigates the developmental processes by which consumers become more or less materialistic. It begins with a review of Inglehart's work in this area, and then applies his theories to explain conceptions of materialism developed by Richins and Belk. Inglehart predicts that the subjective experience of economic deprivation and insecurity during one's formative years leads to adult materialism. Early subjective experiences of deprivation and insecurity strongly predict materialism as conceptualized by Belk, but are not related to materialism as conceptualized by Richins. Inglehart also allows for the social influence of family and peers to shape materialistic orientations. Findings indicate that the formative social influence of family and peers predicts both Belk's and Richins's materialism. This difference between Belk's and Richins's materialism is explained on the grounds that Belk's materialism reflects personality whereas Richins's reflects personal values.
\end{abstract}

As markets gain worldwide dominance as models for social organization, as advertising grows ever more pervasive, and as children and adolescents increasingly take on the role of consumers; it is common to hear the cry that we are becoming increasingly materialistic. Consumer research on materialism has focused on conceptualizations developed by Belk (1982, 1983. 1985; Belk \& Ger, 1995; Ger \& Belk, 1996) and Richins (e. g., Fournier \& Richins, 1991; Richins, 1994a, 1994b; Richins \& Dawson, 1992). The social urgency of this work has been augmented by the well replicated finding that materialism is associated with lower levels of subjective well-being (Sirgy, 1997; Sirgy, Lee, Larsen, \& Wright, 1998; Wright \& Larsen, 1993), although the validity of this relation has recently come under attack (Mick, 1996). Conservationists have also become concerned with the spread of consumer society and materialism, because high levels of consumption are widely seen as the ultimate driving force behind ecological degradation (Princen, 1977).

Requests for reprints should be sent to Aaron C. Ahuvia, Department of Marketing-Dearborn, School of Management, University of Michigan, Dearborn, MI 48128-1491. E-mail: ahuvia@umich.edu
Given this widespread concern with materialism, it is important to understand the socialization process that leads people to become more or less materialistic (Larsen, Sirgy, \& Wright, 1999). Television, and more specifically advertising, is widely seen as a possible cause of materialism (Pollay, 1987; Richins, 1987, 1996) and some empirical work supports this contention (O'Guinn \& Shrum, 1997; Sirgy, Lee, Kosenko, et al., 1998; Wu, 1998). Other writers point to large scale social trends like women's participation in the labor force (Greenberger \& Steinberg, 1986), lower levels of religiosity (Lesthaeghe \& Meekers, 1986; Preston, 1986; Thornton, 1989), and an increase in work and spending by high school students (Bachman, 1983; Freedman \& Thornton, 1990; Greenberger \& Steinberg, 1986). Researchers have also looked within the family at parental values and family environment (Kasser, Ryan, Zax, \& Sameroff, 1995), family structure (Rindfleisch, Burroughs, \& Denton, 1997), and interaction effects between family communication patterns, motives for media consumption, and amount of media consúmption (Moschis, 1978, 1987; Moore \& Moschis, 1981; Moschis \& Moore, 1979; Ward \& Wackman, 1971) as predictors of materialism. However, in the wider academic community, probably the most influential theory on materialistic 
socialization comes from Ronald Inglehart. Since his original publication of the materialism and postmaterialism thesis (Inglehart, 1971), Inglehart has published a stream of books (Abramson \& Inglehart, 1995; Inglehart, 1977, 1990) detailing his conception of materialism, and providing evidence for what he sees as the economic causes underlying materialistic socialization. This research has been widely influential, so much so that a recent search of the Social Sciences Citation Index revealed over 2,200 academic citations of Inglehart's work.

This article discusses the differences between conceptualizations of materialism developed by Inglehart, Richins, and Belk. It then describes Inglehart's developmental theory of materialistic socialization and tests the hypothesis that this theory can help explain the origins of materialism as understood in consumer psychology. In so doing, this article clarifies some of the relations between the two leading consumer psychological definitions of materialism and looks in more detail at the relation between materialism and subjective well-being.

\section{INGLEHART'S, RICHINS'S, AND BELK'S MATERIALISMS}

Before describing Inglehart's theory of materialistic socialization, we need to understand how his definition of materialism differs from work done in consumer psychology by Belk and Richins. Belk originally viewed materialism as a collection of three personality traits: envy, nongenerosity, and possessiveness (Belk, 1985). A fourth trait, preservation, was added in subsequent cross-cultural studies of the materialism scale (Ger \& Belk, 1996). Preservation is a tendency to make experiences tangible through souvenirs and photographs. Because of its focus on materialism as a system of personality traits, Belk's construct will be referred to as personality materialism. ${ }^{1}$

Richins sees materialism as a system of personal values (e.g., Fournier \& Richins, 1991; Richins, 1994a, 1994b; Richins \& Dawson, 1992). Values are enduring beliefs about what is fundamentally important, and are frequently divided into two types: personal and social. Personal values describe what people want for themselves as individuals, whereas so-

\footnotetext{
'Although it is difficult to distinguish personality traits from an individual's underlying value system, it is possible to see that traits such as envy and nongenerosity have an affective component that is lacking in the personal values conceptualization, which operationalizes materialistic values as a set of beliefs as opposed to feelings. For example, an item from Richins and Dawson's (1992) happiness subscale reads as follows: "My life would be better if I owned certain things that I don't have," whereas an item from Belk's (1985) envy subscale reads as follows: "When friends have things I cannot afford it bothers me." This is also consistent with the operationalization of personality traits in the social psychology literature (e.g. Larsen \& Diener, 1987).
}

cial values describe how people think society as a whole should look (Mueller \& Wornhoff, 1990). Richins defines materialism as a personal value stressing the importance of owning material possessions. Richins divides materialism into three parts: centrality, happiness, and success. Centrality is the general importance materialists attach to possessions and the idea that possessions play a central role in thcir lives. Happiness is the belief that owning the right possessions leads to well-being, and that one would be happier if one had more or better things. Finally, Richins defines materialists as people who believe success can be judged by the things people own. In this article, the authors refer to Richins's construct as personal values materialism.

Inglehart is a political sociologist, and as such, he defines materialism more broadly than is customary in consumer psychology (Hellevik, 1993, p. 223). Inglehart sees materialism as a chronic focus on lower order needs for material comfort and physical safety over higher order needs such as self-expression, belonging, aesthetic satisfaction, and quality of life (Inglehart, 1990, pp. 66-68). This definition is consistent with the traditional notion that materialists emphasize worldly ambitions over spiritual matters (Oxford English Dictionary, 1989, Vol. 9, p. 466, as cited in Richins \& Rudmin, 1994), but secularizes this definition by substituting self-actualization for spirituality. In Inglehart's terminology, the opposite of a materialist is a postmaterialist, someone who places great emphasis on satisfying higher order needs, even at the expense of financial rewards. A prototypical postmaterialist would be the artist who forgoes financial rewards in pursuit of his or her higher order needs for personal freedom, aesthetic expression, and self-actualization. Postmaterialism is not asceticism: postmaterialists do not reject wealth, but they give it a lower priority than nonmaterial satisfactions.

In developing his measure of materialism and postmaterialism, Inglehart began with Maslow's hierarchy (Maslow, 1970), and then developed items to measure social values that reflect Maslow's needs. For instance, because materialists give priority to the lower order needs of sustenance and safety, they should see economic growth, low crime rates, and a strong national defense as important social values. Similarly, because postmaterialists give priority to higher order aesthetic, intellectual, belonging, and esteem needs, they place a high importance on social values such as protecting freedom of speech; giving people more say in community, workplace, and government decisions; and of having a less impersonal society where ideas matter more than money. From these examples we can see that Inglehart's definition of materialism refers to a broad-based sociopolitical orientation, rather than being narrowly focused on consumption. Therefore, Inglehart's materialism will be referred to as sociopolitical materialism and postmaterialism. Because Inglehart's definition of materialism extends beyond the boundaries of consumer psychology, we introduce his developmental theory-based model to guide understanding of the origins of materialism as defined by Richins and Belk. 


\section{INGLEHART'S THEORY OF MATERIALIST SOCIALIZATION}

Inglehart provides a compelling, although admittedly partial, explanation of why some individuals and societies are more materialistic than others. Inglehart sees sociopolitical materialism and postmaterialism as the outcome of formative experiences of deprivation or affluence. Put simply, when people grow up in economically deprived environments they internalize a subjective sense of economic insecurity. When they become adults, this sense of economic insecurity stays with them and leads them to place a high value on material success (i.e., become materialists). Conversely, people who grow up with a subjective sense of economic security develop the lasting assumption that money is not something one needs to worry much about. As adults this translates into a "postmaterialistic" orientation in which they feel free to pursue self-actualization even at the expense of material achievement. ${ }^{2}$

Adult materialism is linked to formative feelings of economic insecurity, but "there is no one-to-one relation between economic level and the prevalence of materialist values, for these values reflect one's subjective sense of security, not one's economic level per se" (Inglehart, 1990, p. 68, italics added; see also Inglehart, 1977, p. 137). Inglehart refers to one's subjective sense of economic well-being as "formative affluence," or as "formative security" (Inglehart, 1990, pp. 121-124), but we will refer to it as felt formative affluence or felt formative deprivation to emphasize that it is a psychological experience rather than an economic fact. This is important because it suggests the need to measure people's subjective feelings of affluence, rather than simply measuring their objective economic circumstances. To date, however, all empirical work on Inglehart's theory has used economic data to infer felt formative affluence and deprivation, rather than looking at self-reported subjective experience. Inglehart's early work used generational differences (e.g., children of the great depression vs. baby boomers) as a proxy for felt formative affluence and deprivation (Inglehart, 1971, 1977, 1979, 1990). Later, Inglehart (1979) looked at differences in social class within a single generation (Abramson \& Inglehart, 1996). Most recently, Inglehart has compared the populations of rich versus poor countries to argue that differences in felt formative deprivation between countries explain cultural differences (Abramson \& Inglehart, 1995). One contribution of this article is to introduce a measure of formative felt affluence and deprivation that can be used to more directly measure the influence of this construct on materialism.

\footnotetext{
'Inglehart's theory is nol unique in taking this approach. When applied to class differences. Inglehart's theory is similar to work by Bourdieu (1984) and Holt (1998). Data linking respondents' social class to their material social values confirm this connection (Abramson \& Inglehart, 1996).
}

HI: Felt formative affluence should be negatively related to materialism. This should be true for both ( $\mathrm{H} / \mathrm{a}$ ) personal values materialism and ( $\mathrm{H} 1 \mathrm{~b})$ personality materialism.

\section{The Relative Impact of Felt Formative Experiences on Personality Materialism and Personal Values Materialism}

As a measure of personality, Belk's scale relies heavily on indicators of typical emotional reactions that begin with phrases such as the following: "I enjoy ...," "I don't like ...," "I get very upset if < ...," "I am bothered when ...," and so forth. In contrast, Richins's scale of personal values materialism is primarily an assessment of respondents' cognitive beliefs about the relative importance of various personal priorities. This distinction is important because the extent to which a materialism construct involves affect as opposed to cognition has implications for the types of antecedent variables that are likely to influence it. Recall that Inglehart's theory is based on a three-step process: economic difficulties $\rightarrow$ felt formative deprivation $\rightarrow$ materialism. However, personal values materialism is primarily a cognitive construct. Felt formative deprivation can only affect personal values materialism after a complex interpretive process, in which individuals understand their feelings, and formulate personal values based on them. Inglehart suggested that the dominant form of reasoning is as follows: I feel deprived $\rightarrow$ I want to become more affluent. However, this is not the only set of values that could arise from feeling deprived. One might also reason thus: I feel deprived $\rightarrow$ I want to feel better $\rightarrow$ I will devalue the financial success that I cannot easily attain. This illustrates that the more cognitive is the response to felt formative experiences, the "noisier" and more uncertain this process will be. Unlike Richins' personal values materialism, Belk's personality materialism is based largely on gut-level emotional responses. The specific emotional responses making up personality materialism are very plausibly the outcomes of subjective feelings of deprivation-envy, nongenerosity, and possessiveness. Because abstract cognitive beliefs play a smaller role in personality materialism than they do in personal values materialism, personality materialism should be more influenced by felt formative experiences. Perhaps this is why Maslow (1970) used need satisfaction to explain personality, not social values.

This discussion does not imply that affect and values are unrelated, arising from totally different sources (Sorrentino \& Higgins, 1986). On the contrary, "through a continuous interaction with the environment in its physical, cultural, and social manifestations, individuals develop a total integrated system of mental structures and contents that shape and constrain their modes of functioning" (Magnusson, 1990, p. 199). However, this integrated system is composed of various parts, and it is reasonable to hypothesize that need satisfaction has a greater impact on personality than it does on more cog- 
nitive constructs like social values. So, although $\mathrm{HI}$ states that felt formative deprivation should influence both forms of materialism, $\mathrm{H} 2$ addresses the relative strength of its influence on each form.

H2: The influence of felt formative deprivation on materialism should be stronger for personality materialism than for personal values materialism.

\section{The Social Milieu and the Origins of Materialism}

Despite Inglehart's primary emphasis on formative felt affluence, he also allows for the possibility that materialism may be shaped by the social milieu that prevailed during one's formative years (Inglehart, 1977). By "social milieu" we mean the values internalized through interactions with peer groups, role models, and the media (Moschis, 1987). Whereas formative felt affluence focuses on whether individuals feel that their needs are being met, the formative social milieu refers to the lessons an individual learns from the community.

In most cases, felt formative experiences and the formative social milieu are complementary forces on a person's development. However, when an individual's economic circumstances differ from the prevailing economic circumstances, need satisfaction and the formative social milieu predict different results. Imagine a girl growing up in a middle-class community during a period of general prosperity, but whose parents' business was in dire straits. Although she might often feel that her needs were going unmet, at school and in the media she would hear messages reflecting postmaterialist values. Need theory would predict that she would tend toward materialism, whereas social influence would predict the opposite. Therefore, it is desirable to separately measure felt formative affluence and respondents' perceptions of the formative social milieu in which they grew up, so that the impact of each can be assessed. Hypotheses relating felt formative deprivation to materialism have been stated earlier. Hypothesis 3 relates the social milieu to materialism.

H3: The formative social milieu, as reflected in the perceived materialism of socialization agents with whom respondents identified, should be positively related to respondents' own levels of materialism. This should be true for $(\mathrm{H} 3 \mathrm{a})$ personal values materialism and (H3b) personality materialism.

\section{Formative Felt Deprivation and Current Life Satisfaction}

The relation between materialism and lower levels of life satisfaction is one of the most interesting and least understood findings from this literature (Belk, 1985; Kasser, 2002;
Kasser \& Ryan, 1993; Richins \& Dawson, 1992). If Inglehart's theory that materialism arises from formative experiences of felt deprivation is correct, then this theory can help explain why materialists suffer lower levels of subjective well-being in three related ways. First, materialists' lower levels of life satisfaction may be due, at least in part, to a lingering sense of dissatisfaction with their ability to meet their lower order needs left over from these carlicr formative experiences (Marsh, 1975). This suggests H4.

H4: People who score high on materialism should tend to be dissatisfied with their lower order needs. This should be true for $(\mathrm{H} 4 \mathrm{a})$ personal values materialism and (H4b) personality materialism.

Second, materialists' chronic sense of dissatisfaction with their lower needs may be aggravated by a tendency to place a high priority on these needs when assessing the overall success of their lives (Inglehart, 1977, pp. 116-147; La Barbera \& Gurhan, 1997). In this way, materialists are doubly vexed by intransigent feelings of material deprivation aggravated by a tendency to place issues of material success at the center of their identity. This suggests H5.

H5: The more materialistic one is, the more one's overall life satisfaction should be dependent on satisfying one's lower order needs. This should be true for (H5a) personal values materialism and ( $\mathrm{H} 5 \mathrm{~b})$ personality materialism.

Third, Inglehart's developmental theory also has implications for the ability of materialists to meet their higher order needs. Much of the literature sees materialists as people who attach greater importance to possessions than to people, leading to unsatisfying interpersonal relationships (Fournier \& Richins, 1991; Kasser \& Ryan, 1993; Richins \& Dawson, 1992). This implies that materialism results not only in dissatisfaction with one's lower order needs, but in an inability to meet one's higher order needs, particularly the need for love and significant personal relationships. This does not necessarily contradict $\mathrm{H} 4$ and $\mathrm{H} 5$ : it is quite possible for materialists to be less satisfied with both their lower order needs and their higher order needs. However, it does raise the issue of the relation between materialism and higher order need satisfaction, suggesting $\mathrm{H} 6$.

H6: People who score high on materialism should tend to be dissatisfied with their higher order needs. This should be true for (H6a) personal values materialism and (H6b) personality materialism.

Taken together, Hypotheses 4, 5, and 6 paint a picture of materialists that is consistent with Inglehart's developmental theory. Early experiences of felt formative deprivation leave materialists with a lingering sense of material dissatisfaction 
(H4) and an increased priority on attaining material rewards (H5). This, in turn, leads to a neglect of interpersonal relationships and other mechanisms for meeting their higher order needs, yielding dissatisfaction in these areas as well (H6).

\section{METHODOLOGY}

\section{Respondents}

Data were collected in two waves at two Midwestern universitics. Completed questionnaires were collected from a total of 287 students ( 133 women). At the first university, respondents were juniors and seniors enrolled in undergraduate marketing courses (139 students, including 58 women). At the second university, respondents were from all undergraduate levels (148 students, including 75 women).

\section{Measures}

Personal values materialism. Personal values materialism was measured using the materialism scale of Richins and Dawson (1992). This measure consists of three subscales: (a) acquisition centrality, (b) happiness, and (c) success. Confirmatory factor analysis was conducted to examine the reliabilities, convergent validity, and uniqueness of the subscales. The coefficient as were $.73, .74$, and .76 for success, centrality, and happiness dimensions, respectively. Overall coefficient $\alpha$ was .82, indicating satisfactory reliability. A partial aggregation approach was used whereby individual items are combined to form two indicators of each factor. This approach is preferred in the case of a multidimensional construct such as materialism or self-efficacy while maintaining consistency in the level of abstraction across all dimensions (Bagozzi \& Heatherton, 1994). The resulting Comparative Fit Index (CFI) was .99 and Non-normal Fit Index (NNFI) was .98 with significant factor loadings and there was little variance to be explained (Root Mean Square Error of Approximation; RMSEA $=.048$ ). Values of .90 or greater for the CFI and NNFI are generally considered satisfactory and both measures are not sensitive to sample size (Marsh, Balla, \& Hau, 1996). Factor correlations and factor loadings of this analysis are listed in Figure 1.

Personality materialism. Personality materialism was measured using Ger and Belk's (1996) revised materialism scale. Their cross-cultural study on materialism modified and expanded some scale items from Belk's (1985) original materialism.scale. The modified personality materialism scale includes four subscales: (a) possessiveness, (b) nongenerosity, (c) envy, and (d) preservation. Confirmatory factor analysis was conducted to examine the reliabilities, convergent validity, and uniqueness of the subscales. The

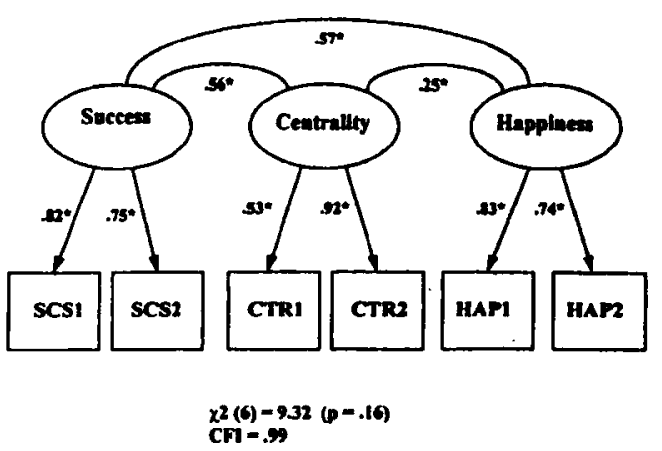

FIGURE 1 Measurement model for personal values materialism.

preservation subscale, which yielded a negative factor loading (-.28) on Belk's materialism scale, was excluded from future analyses, because it did not fit the original conceptualization of Belk's materialism scale. Coefficient $\alpha$ for nongenerosity, envy, and possessiveness dimensions were $.71, .57$, and .44 , respectively. The overall coefficient $\alpha$ was .71. Because the reliabilities of the subscales were not satisfactory, the overall scale was used and the items were therefore combined to form a single indicator for the construct, a total aggregation approach.

Felt formative deprivation. Because established scales to measure subjective deprivation during childhood and adolescence were not available, measures were created for this study. Four items were generated to measure felt economic well-being. Respondents completed these items twice, once for ages 0 to 12 and once for ages 13 to 18 (see Figure 2). Items were marked on a 5-point scale, ranging from strong disagreement to strong agreement. High scores on this scale indicated high levels of felt economic deprivation. The test-retest reliability was assessed in a pretest with 50 participants over a 6-week period. Test-retest reliability was quite satisfactory at $r=.65$ for childhood felt formative deprivation items, and $r=.54$ for teenage felt formative deprivation items.

Exploratory factor analysis yielded two factors for the two age periods that accounted for $60 \%$ of the variance. Coefficient $\alpha$ for the four items in age 0 to 12 and age 13 to 18 were .73 and .71 , respectively. Although a combined measure of felt formative deprivation could be used, a partial aggregation measurement model with two factors (each represented by summing the four items in each age period, 0-12 and 13-18) was tested to maintain consistency in the level of abstraction across all constructs (Bagozzi \& Heatherton, 1994). Because similarly worded items were likely to be correlated, the measurement model also included correlational paths between the two similarly worded items in both age periods. Finally, results of confirmatory factor analysis showed this model to be acceptable, according to the criteria outlined earlier, $\chi^{2}(15)=$ 


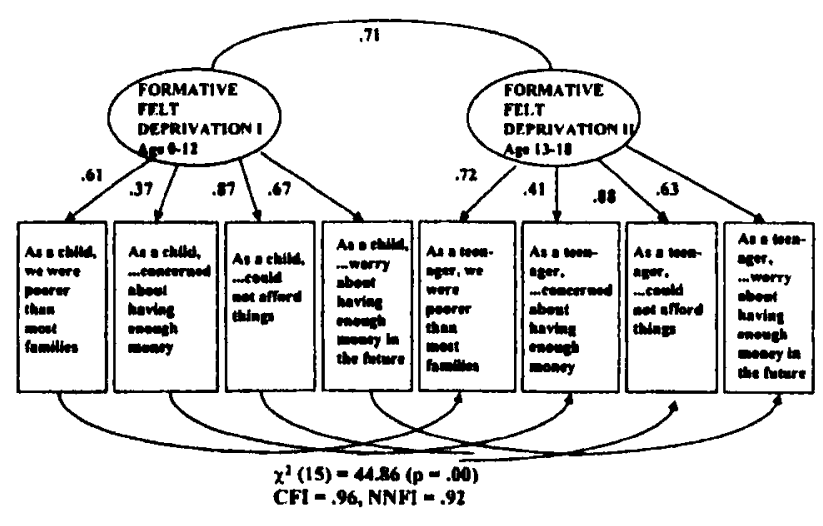

FIGURE 2 Measurement model for felt formative deprivation.

$44.86, p=.00, \mathrm{CFI}=.96, \mathrm{NNFI}=.92$. See Figure 2 for the two-factor measurement model.

The formative social milieu. To understand the impact of the formative social milieu in value acquisition, the messages respondents received from socialization agents (important others around the respondents) must be examined. The messages respondents received while growing up can then be compared to respondents' current levels of personal values materialism and personality materialism. This approach is consistent with existing studies of socialization, which typically compare the relations between the values held by respondents and their socializing agents (Bengston, 1975). Ideally, this would be done through a longitudinal study, but recall-based data is acceptable in the initial phases of theory development. Three aspects of this study mitigate some common problems with recalled data. First, the measures used in this research asked respondents to rate the extent to which various socialization agents resembled widely held prototypes within our society (see Figure 3 for the item referring to the respondents father). Because it is a fairly common practice in our culture to categorize people in this way, it is likely that respondents could complete this task with a reasonable degree of accuracy. Second, there is no obvious or direct relation between measures depicted in Figure 3 and the measures for personality or personal values materialism, thus reducing the likelihood of spurious correlations. Third, just as we are concerned with felt formative affluence rather than a person's objective economic circumstances, we are concerned with the way the respondents perceived the socialization agents around them (the subjective norm), rather than the actual attitudes of these persons.

The key socializing agents are family, school, peer group, and the mass media (Bengston, 1975; Corsaro \& Elder, 1990; Elkin \& Handel, 1988; Moschis, 1987, pp. 72-176). Figure 3 depicts the item measuring the perceived value priorities of the respondent's father. Similar items measured the perceived material values of the respondent's mother, parents' friends, teachers, religious leaders, local adult community as a whole, heroes or adults admired, same sex friends, opposite sex friends, and friends in general. Exploratory factor analysis yielded three factors accounting for $56 \%$ of the variance. The first factor that emerged consisted of items measuring the perceived material values of the respondent's father, mother, parents' friends, and the local adult community; the second factor contained perceptions about the respondent's same sex friends, friends in general, and heroes and people that one admires; and the last factor consisted of perceptions about religious leaders, teachers, and opposite sex friends. Coefficient a for the three factors were $.70, .69$, and .39 , respectively. Due to the low reliability, the last factor was not included in the analysis. ${ }^{3}$ The remaining two factors were labeled family group and social group. This two-factor model was also tested using confirmatory factor analysis, and was found to be acceptable, $\chi^{2}(13)=33.31, p=.001 ; C F I=.95$; $\mathrm{NNFI}=.91$. Mass media influences do not play a major role in Inglehart's theory, and are therefore beyond the scope of this study. Figure 4 shows the measurement model on formative social milieu measures as well as the factor loadings and factor correlation of these indicators.

Andrews and Withey Life Satisfaction Measure. Andrews and Withey's (1976) 6-item measure of subjective well-being was used in the study. This instrument has been used in past studies (Inglehart, 1977; Richins, 1987; Richins \& Dawson, 1992). The six items measure feelings of well-being about the following: (a) life as a whole; (b) amount of fun and enjoyment; (c) family, friends, and work [ work was changed to studies for these student samples]; (d) income level; (e) standard of living; and (f) relationships with friends. Respondents were asked to rate on a 7-point scale (ranging from terrible to delighted) how they felt about life as a whole, how much fun and enjoyment they were having, and so forth. Exploratory factor analysis was conducted and two factors emerged that accounted for $70 \%$ of the variance. The first factor consisted of items (1), (2), (3), and (6). Items (2), (3), and (6) were combined to form HNEEDS (satisfaction with higher order needs; alpha $=.74$ ), whereas item (1) is used as a summary measure of life satis-

\footnotetext{
"Past research has shown that the extent of identification is closely related to the degree of social influence that a socialization agent can exer (Becherer \& Morgan, 1982; Moschis, 1976). For these three groups of socialization agents (teachers, religious leaders, and opposite sex friends), it appears that the degree of identification was generally so low that these measures were negatively correlated with other items. As to the influence of religious leaders, some respondents wrote margin notes indicating their lack of religious affiliation; often, the item was left blank. Regarding influence by opposite sex friends, it appears that, although many of the respondents feel that they want to be attractive to their opposite sex friends, they don't necessarily want to be like them. Finally, teachers may be perceived as authoritative figures to be rebelled against, or at least very distant socially, and not someone with whom the respondents would want to be identified. Because these three items apparently represented categories of people with whom many of the respondents did not identify, they were dropped from the social influence measures.
} 
As I was growing up, my FATHER felt that ...

"Over the next ten years this country should aim to:"

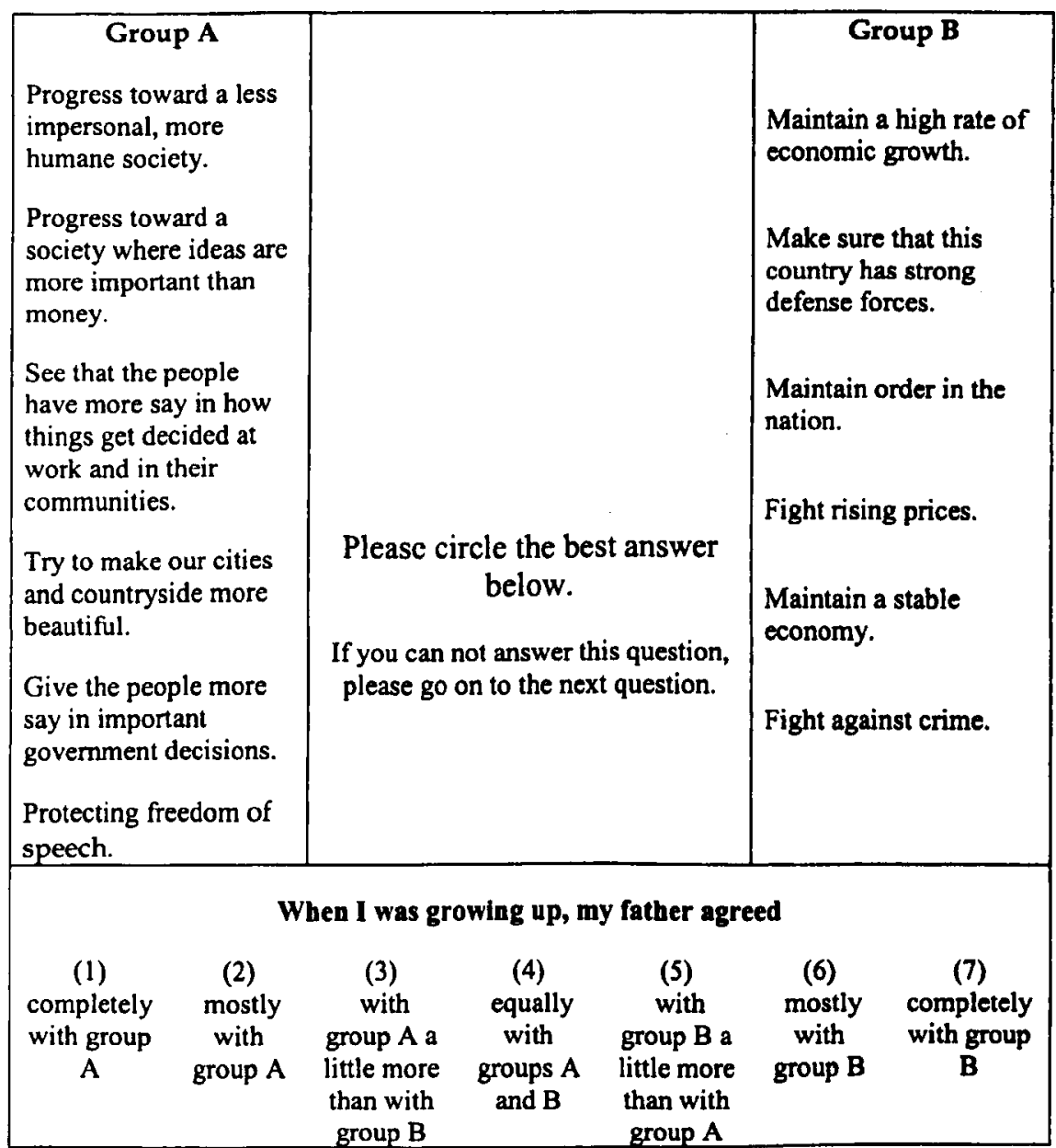

FIGURE 3 Formative social milieu measure for father.

faction. Items (4) and (5) emerged as a second factor and were combined to form LNEEDS (satisfaction with lower order needs; correlation $=.54$ ). Confirmatory factor analysis of the two-factor model yielded a satisfactory model with $\chi^{2}(4)=$ $11.68, P=.02, \mathrm{CFI}=.97$, and NNFI $=.93$, indicating an acceptable fit. Figure 5 shows the measurement model for higher order and lower order needs measures as well as the factor loadings and factor correlation of these indicators.

Socioeconomic status measure. Respondents' socioeconomic status (SES) is based on a combination of three dimensions: (a) reported family annual income level, (b) father's education, and (c) mother's education. Following established practice, these variables are combined into an overall measure of SES by averaging subjects' summed standardized scores for these measures (Rindfleisch et al.,
1997). Coefficient alpha for the combined measure was .60, acceptable for this type of exploratory study (Nunnally, 1978), especially when one considers that these are correlations between demographic variables rather than psychometric items.

\section{RESULTS AND DISCUSSION}

\section{Felt Formative Deprivation and the Origins of Materialism}

A simultaneous test of several hypotheses was conducted using a structural equations model (see Figure 6), which uses felt formative deprivation and formative social milieu measures as antecedents to the materialism measures. The model fit is acceptable $\cdot \chi^{2}(14)=35.85, p=.001$, and RMSEA $=.07$. 


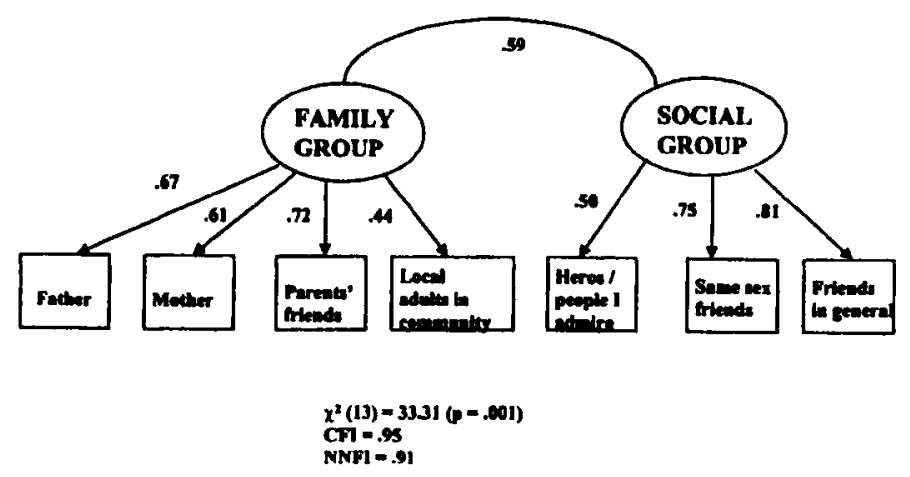

FIGURE 4 Measurement model for fomative social milieu.

This is further confirmed by NNFI $=.89$ and CFI $=.94$. All factor loadings for both exogenous and endogenous indicators average .68, all are statistically significant, and the error variances are low to moderate.

H1 applies Inglehart's developmental theory to Richins's and Belk's constructs of materialism. That is, felt formative deprivation should lead one to place a greater value on material possession, which should be reflected in higher levels of $(\mathrm{Hla})$ personal values materialism and (HIb) personality materialism. Figure 6 shows that the causal path from felt formative deprivation to personal values materialism is positive $(\gamma=.09$, s.e. $=.07)$, but not significant, disconfirming Hla. ${ }^{4}$ However, the causal path from felt formative deprivation to personality materialism is both positive and significant $(\gamma=.15$, s.e. $=.07)$.

Although the failure of formative felt deprivation to significantly influence personal values materialism was unexpected, it is nonetheless generally consistent with $\mathrm{H} 2$ which proposes that felt formative deprivation should exert a greater influence on personality materialism than on personal values materialism. Figure 6 shows that the magnitude of the causal paths between felt formative deprivation (FFD) decreases as one moves from personality materialism $(\gamma=.15, \mathrm{SE}=.07)$ to personal values materialism, $(\gamma=.09, \mathrm{SE}=.07)$. The fact that $\gamma_{\text {formative felt deprivation-personality materialism was significant }}$ whereas $\gamma_{\text {formative felt deprivation-personal values materialism was }}$ not, certainly suggests that $\mathrm{H} 2$ is on track. However the difference between these two gammas, whereas in the predicted direction, was not large enough to reach statistical significance. ${ }^{5}$

\footnotetext{
A total aggregation model using a combined scale for personal values materialism was also tested but yielded essentially similar results. For purpose of consistency, only the partial aggregation model is shown here.

${ }^{3}$ Chi-square difference lest of equal gammas (i.e., Yrormulve iell deprivation-per.

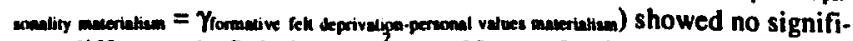
cant difference in fit indexes $\left(\chi^{2} d=1.20, p<.50\right)$ from Figure 6.
}

\section{Social Influence and the Origins of Materialism}

H3 hypothesizes that materialism is learned through the standard socialization process in which the child takes on the values and attitudes of the socialization agents with which he or she identifies. The causal path from social milieu to personal values materialism is positive and statistically significant [ $\gamma_{\text {social milieu - personal }}$ values materialism $=.38,(\mathrm{SE}=.10)]$, as is the causal path from social milieu to personality materialism $\left[\gamma_{\text {social mi- }}\right.$ lieu - personal values materialism $=.18,(\mathrm{SE}=.07)]$, confirming $\mathrm{H} 3 \mathrm{a}$ and $\mathrm{H} 3 \mathrm{~b}$. This finding is particularly important given the failure of formative felt deprivation to predict personal values materialism, because it helps answer the following question: "If formative felt deprivation does not predict personal values materialism, what does?" Figure 6 shows that the more affective- and personality-based aspects of materialism (Belk's measure, 1985) stem both from early experiences of felt deprivation and the role modeling of socialization agents, whereas the more cognitively based personal values materialism (Richins \& Dawson's measure, 1992) is related primarily to the socialization process involving role models.

\section{Materialism and the Satisfaction of Lower Versus Higher Order Needs}

Both $\mathrm{H} 4$ and $\mathrm{H} 5$ examine the relation between materialism and the satisfaction of lower order needs. H4 hypothesizes that high materialists are likely to be less satisfied with their lower order needs (income and possessions) than are low materialists. Table 1 shows that H4 was supported for (H4a) personal values 


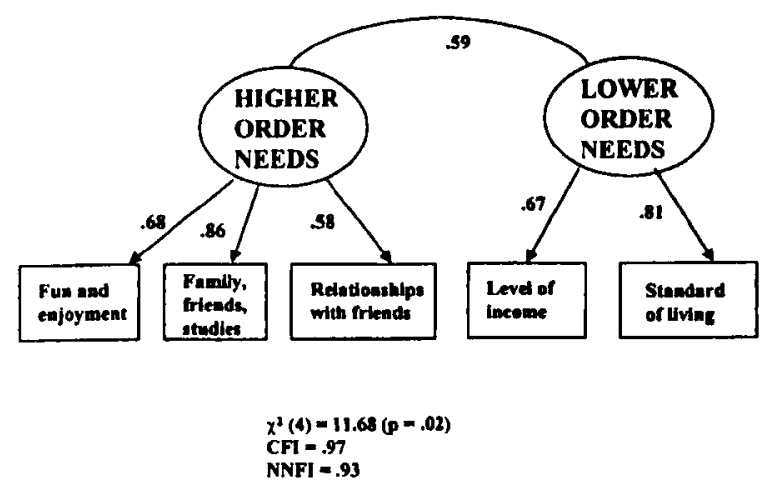

FIGURE 5 Measurement model for higher order and lower order needs.

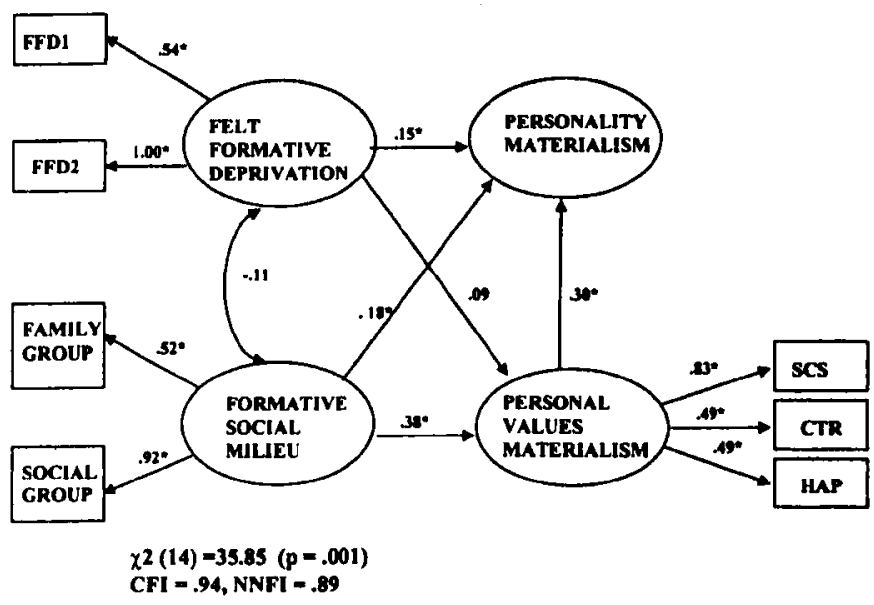

FIGURE 6 Effects of felt formative deprivation and formative social milieu on materialisms.

materialism ${ }^{6}$ ( 4.92 vs. $\left.4.64, p=.05\right)$, and ( $\left.\mathrm{H} 4 \mathrm{~b}\right)$ personality materialism (5.02 vs. $4.53, p=.0005)$.

These findings are consistent with the idea that individuals who subjectively experience insecurity and deprivation in their formative years develop a lasting sense of dissatisfaction with their material condition that manifests itself as adult materialism. However, these findings could also be explained by the respondent's current economic situation, that is, people who are currently experiencing a low standard of living might be dissatisfied with their money and possessions and

\footnotetext{
'Contrary to past research, respondents who scored high on personal values materialism were not less satisfied with their lives as a whole ( 5.35 vs. $5.31, p=.78$ ). However, replicating past findings, respondents who scored high on personality materialism were less satisfied with their lives as a whole (5.02 vs. $4.53, p=.0005$ )
}

therefore score high on materialism. To rule out this rival explanation, multiple regression analysis was conducted using satisfaction with lower order needs as the dependent variable and personal values materialism, personality materialism, and social class as predictors. For student respondents, personal income data is difficult to interpret, so their families' social class was seen as the best indicator of their current standard of living. Table 2 shows that for personal values materialism ( $\mathrm{H} 4 \mathrm{a})$, high materialists tend to be less satisfied with their lower order needs, but the statistical significance of the relation is borderline $(\beta=-.24, p=.06)$. For personality materialism, the relation was also in the predicted direction and reached statistical significance $(\beta=-.64, p=.0003)$, thus $\mathrm{H} 4 \mathrm{~b}$ is supported. Finally, as expected, one's SES also has a positive and significant influence $(\beta=.33, p=.0006)$ on satisfaction with lower order needs, supporting the relevance of this measure. Thus, materialism has a negative impact on satisfac- 
TABLE 1

Test of Mean Differences Between High Versus Low Materialism

\begin{tabular}{lcccc}
\hline Measure & Low & High & t-value & $p$-value \\
\hline Personal Values Materialism & $(\mathrm{N}=137)$ & $(\mathrm{N}=144)$ & & \\
Satisfaction with lower order needs & $4.92(1.16)$ & $4.64(1.25)$ & 3.90 & .05 \\
Satisfaction with higher order needs & $5.22(1.01)$ & $5.31(1.01)$ & .55 & .46 \\
Overall life satisfaction & $5.35(1.13)$ & $5.31(1.12)$ & .08 & .78 \\
Personality Materialism & $(\mathrm{N}=139)$ & $(\mathrm{N}=145)$ & & \\
Satisfaction with lower order needs & $5.02(1.16)$ & $4.53(1.21)$ & 12.26 & .0005 \\
Satisfaction with higher order needs & $5.50(0.90)$ & $5.05(1.05)$ & 14.84 & .0000 \\
Overall life satisfaction & $5.57(0.99)$ & $5.10(1.19)$ & 12.74 & .0004 \\
\hline
\end{tabular}

Note. Standard deviations are listed in parentheses.

TABLE 2

Relationships Between Materialism, Socioeconomic Status on Satisfaction With Lower Order Needs

\begin{tabular}{|c|c|c|c|}
\hline Dependent Variables & Independent Variables & Coefficient $\alpha$ & $p$ \\
\hline \multirow{3}{*}{$\begin{array}{l}\text { Satisfaction with lower or- } \\
\text { der needs (LNEEDS) }\end{array}$} & Socioeconomic status (SES) & .33 & .0006 \\
\hline & $\begin{array}{l}\text { Personal values materialism } \\
\text { (MRICH) }\end{array}$ & -.24 & .06 \\
\hline & $\begin{array}{l}\text { Personality materialism } \\
\text { (MBELK) }\end{array}$ & -.64 & .0003 \\
\hline
\end{tabular}

Note. $F$ value $=11.77, p=.0000, \mathrm{R}^{2}=.10$

tion with lower order needs, even after controlling for one's current standard of living.

Personal values materialism has three subscales: success, centrality, and happiness. An examination of these subscales shows that the negative relation between personal values materialism and satisfaction with lower order needs was driven exclusively by the happiness dimension (see Table 3). Most of the items that measure happiness read "I would be happier if I could afford to buy more things," and so forth. In fact, all five items discuss the relations between happiness and having more things to enjoy life. Therefore, it is plausible that the negative relation was mostly driven by this connection between happiness and possessions, a lower order need. This finding is consistent with past work, which has found the happiness subscale to be the primary driver of the relation between personal values materialism and lower levels of subjective well-being (Ahuvia \& Wong, 1995).

Personality materialism also has three subscales: envy, nongenerosity, and possessiveness. The negative relation between personality materialism and satisfaction with lower order needs was driven by envy and nongenerosity. This makes sense; people who feel dissatisfied with their material situation are likely to feel envious of others and be disinclined to share what they have. It also stands to reason that people who feel dissatisfied with their material situation should be highly protective of what they have (possessive). However, although the relation between dissatisfaction with one's lower order needs and possessiveness was in the predicted direction, it failed to reach significance (see Table 3).

H5 hypothesizes that the more materialistic one is, the greater role satisfaction of lower order needs will play in one's overall life satisfaction. A hierarchical regression analysis was conducted to test the moderating effect of materialism on satisfaction with lower order needs and satisfaction with one's life as a whole. A test of moderation is performed by entering each predictor variable and followed by the product term for their interaction. Presence of moderation is indicated by a significant 2 -way interaction. Table 4 shows a nonsignificant interaction term for personal values materialism and satisfaction with lower order needs on overall life satisfaction $(\beta=-.07, p=.38)$. $\mathrm{H} 5 \mathrm{a}$ is therefore not supported. However, a marginally significant interaction was found for personality materialism and satisfaction with lower order needs on overall life satisfaction $(\beta=.20, p=.067)$. Thus, $\mathrm{H} 5 \mathrm{~b}$ is partially supported.

H6 hypothesizes that because materialists are fixated with meeting their lower order needs, they may neglect other areas of their lives and therefore be dissatisfied with their higher or- 
der needs as well. For personal values materialism, Table 1 shows no difference in the level of satisfaction with higher order needs for low versus high materialists (5.22 vs. 5.31, $p=$ .46 ), disconfirming H6a. However, for personality materialism, the relation is in the predicted direction and statistically significant ( 5.50 vs. $5.05, p=.000$ ), supporting H6b.

\section{CONCLUSION}

Inglehart proposed a model of materialistic socialization in which formative subjective experiences of economic deprivation and insecurity lead to a lifelong fixation with material needs at the expense of one's higher order needs. This prioritization of lower order needs over higher order needs manifests itself as materialism. This theory was tested by developing a measure of felt formative affluence and deprivation and relating it to Richins and Dawson's measure of personal values materialism and Belk's measure of personality materialism. This test supported the connection between felt formative deprivation and personality materialism, but did not support this connection for personal values materialism (see Table.5).
The idea that adult materialism is linked to formative experiences of felt deprivation also leads to predictions about materialism and satisfaction of lower order versus higher order needs. Specifically, these formative experiences of felt deprivation may lead to a chronic dissatisfaction with one's material situation (H4), a tendency to prioritize lower order needs over higher order needs when assessing one's overall well-being (H5), and a consequent neglect of one's higher order needs, leaving them unsatisfied as well (H6). Table 5 summarizes the findings from this article. It shows a consistent pattern of support for the connection between needs satisfaction and personality materialism, but it generally does not support the connection between needs satisfaction and personal values materialism.

Hypothesis 2 suggests that the influence of felt formative deprivation on materialism should be stronger for personality materialism than for personal values materialism. The evidence for $\mathrm{H} 2$ was mixed. A comparison of the magnitude of the causal paths between felt formative deprivation and personality materialism $(\gamma=.15)$ versus felt formative deprivation and personal values materialism $(\gamma=.09)$ was in the predicted direction, but not statistically significant. However, consistent with $\mathrm{H} 2$, the causal path between felt formative de-

TABLE 3

Correlations Between Materialism and Life Satisfaction Measures

\begin{tabular}{|c|c|c|c|c|c|c|c|c|}
\hline Measures & (l) & (2) & (3) & (4) & (5) & (6) & (7) & (8) \\
\hline Envy (1) & - & & & & & & & \\
\hline Nongenerosity (2) & $.26 * *$ & - & & & & & & \\
\hline Possessiveness (3) & $.18^{* *}$ & $.29 * *$ & - & & & & & \\
\hline Success (4) & $.34 * *$ & $.23 * *$ & $.12^{*}$ & - & & & & \\
\hline Centrality (5) & .07 & .04 & $.13^{*}$ & $.43^{* *}$ & - & & & \\
\hline Happiness (6) & $.41 * *$ & $.28 * *$ & $.19 * *$ & $.40^{* *}$ & $.21 * *$ & - & & \\
\hline LNEEDS (7) & $-.30^{* *}$ & $-.17 * *$ & -.11 & -.08 & .06 & $-.41 * *$ & 一 & \\
\hline HNEEDS (8) & $-.27 * *$ & $-.21^{* *}$ & $-.18 * *$ & -.03 & .09 & $-.19 * *$ & $.41^{* *}$ & 一 \\
\hline
\end{tabular}

$* p<.05{ }^{* *} p<.01$

TABLE 4

Test of the Moderating Effects of Materialism on Satisfaction With Lower Order Needs and Overall Life Satisfaction

Dependent and Independent Variables

Coefficient $\alpha$

$p$

(1) Life satisfaction:

Satisfaction with lower order needs (LNEEDS)

.59

.03

Personal values materialism (MRICH)

.29

.47

LNEEDS X MRICH

$-.07$

.38

(2) Life satisfaction:

Satisfaction with lower order needs (LNEEDS)

$-.23 \quad .45$

Personality materialism (MBELK)

$-1.36$

LNEEDS X MBELK

.20

.067

Note. For the first life satisfaction model, $F=17.35, p<.0000, \mathrm{R}^{2}=.15$. For the second life satisfaction model, $F=22.53, p<.0000, \mathrm{R}^{2}=.19$. 
TABLE 5

Summary of Research Findings

\begin{tabular}{|c|c|c|}
\hline Hypothesis & $\begin{array}{l}\text { Personal Values Materialism } \\
\text { (Richins) }\end{array}$ & $\begin{array}{l}\text { Personality Materialism } \\
\text { (Belk) }\end{array}$ \\
\hline HI: Felt formative affluence should be negatively related to materialism & Not Supported & Supported \\
\hline $\begin{array}{l}\text { H2: The influence of felt formative deprivation on materialism should be } \\
\text { stronger for personality materialism than for personal values materialism. }\end{array}$ & Partially Supported* & Partially Supported* \\
\hline $\begin{array}{l}\text { H3: The formative social milieu should be positively related to respon- } \\
\text { dents' own levels of materialism. }\end{array}$ & Supported & Supported \\
\hline $\begin{array}{l}\text { H4: People who score high on materialism should tend to be dissatisfied } \\
\text { with their lower order needs. }\end{array}$ & Partially Supported** & Supported \\
\hline $\begin{array}{l}\text { H5: The more materialistic one is, the more one's overall life satisfaction } \\
\text { should be dependent on satisfying one's lower order needs. }\end{array}$ & Not Supported & Partially Supported*** \\
\hline $\begin{array}{l}\text { H6: People who score high on materialism should tend to be dissatisfied } \\
\text { with their higher order needs. }\end{array}$ & Not Supported & Supported \\
\hline
\end{tabular}

${ }^{*} \mathrm{H} 2$ is supported by the broad pattern of evidence. But the direct comparison of gammas did not reach statistical significance. ${ }^{* *} p=.060$ $* * * p=.067$.

privation and personality materialism was significant, whereas the path between felt formative deprivation and personal values materialism was not. Support for $\mathrm{H} 2$ is further reinforced by the pattern of evidence described the previous paragraph. H4, H5, and $\mathrm{H} 6$ were all theoretically consistent with the theory that felt formative deprivation leads to adult materialism. As we have seen, $\mathrm{H} 4, \mathrm{H} 5$, and $\mathrm{H} 6$ were generally supported with regards to personality materialism, but were not supported for personal values materialism. Taken as a whole, this pattern of evidence suggests that formative felt deprivation is probably irrelevant in the development of personal values materialism.

However, if formative felt deprivation doesn't lead to personal values materialism, what does? It seems that like other value orientations, personal values materialism is (at least in part) learned through interaction with socialization agents. This form of socialization also appears to play a role in the development of personality materialism.

This article reveals how differences in the affective and cognitive content of these two types of materialism relate systematically to differences in the types of developmental events that are associated with them. The contrast between personal values materialism, where felt formative deprivation may be irrelevant, and personality materialism, where felt formative deprivation seems critical, suggests a symmetry between what goes into an individual in the form of experiences, and what comes out in the form of espoused beliefs and emotional reactions. When emotions go in, emotions come out: that is, early emotional experiences may influence emotional reactions later in life. Feeling materially deprived as one grows up is a very emotion-laden situation. Emotions experienced in one's youth may pattern one's emotional responses into adulthood. Because personality materialism has many items that pick up on emotional responses and tenden- cies, it reflects the emotion-laden outcomes of felt formative deprivation. Because Richins' measure of personal values materialism taps less affective content, it is only weakly related to felt formative deprivation.

In contrast to felt formative deprivation, the social milieu depends heavily (although not entirely) on socialization agents imparting cognitive information to the individual. When cognitive information goes in in the form of social influence, cognitive information comes out in the form of values. This exposure to $\mathrm{cog}$ nitive influence affects personal values, because they have such as strong cognitive component. Although Belk's personality materialism is predominantly affective, it also has a significant cognitive component, which helps explain why it too is significantly correlated with the formative social milieu.

The social influence measures here are specifically tied to whether socialization agents communicated materialist and postmaterialist values to the respondents. This indicates that the sociopolitical materialism and postmaterialism respondents were exposed to growing up predicts the extent of their current materialism, even when materialism is conceptualized quite differently. The connections between these constructs may run fairly deep, and future investigation is warranted. Also, the predictive power of social influence in general may be increased with the development of new measures of social influence that focus on forms of social influence leading to personality materialism or personal values materialism.

Future research could also help correct some of the limitations of this study. Specifically, before the connection between felt formative deprivation and personal values materialism can be ruled out, studies are needed in populations which show greater variance in felt formative deprivation. Although steps were taken to insure variance on this measure, significantly greater variance could be achieved by comparing First World and Third World populations or other 
groups with large income disparities. However, this sample is relevant for understanding the causes of individual differences in materialism within the broad American middle class. Future work may also avoid the reliance on recall measures used in this study. Finally, replication is needed to clarify findings that were borderline in their statistical significance.

One of the most important findings with regard to materialism is the consistent relation between high levels of materialism and low levels of life satisfaction (Ahuvia \& Wong, 1995; Wright \& Larsen, 1993). This study points researchers interested in this issue in several directions. First, personality materialism showed a generally more robust connection to life satisfaction than did personal values materialism. Unfortunately, despite attempts to improve this scale (Ger \& Belk, 1996), it's measurement properties are still less than ideal. Future researchers may wish to scrutinize the connection between this construct and life satisfaction with the aim of developing a new measure. Past researchers have generally treated personal values materialism as a single construct. However, researchers interested in the psychology of subjective well-being may wish to rethink this practice. Table 3 confirms past research (Ahuvia \& Wong, 1995) in showing that the relation between personal values materialism and life satisfaction is almost entirely driven by the Happiness subscale. Future researchers may wish to break out this subscale and treat it as a unique construct, because its relation to dependent variables of interest differs so strongly from the other subscales in this measure.

In a more speculative vein, this work suggests a possible link between research on materialism and on attachment theory (Bowlby, 1973). In attachment theory, formative childhood relationships form the models for adult social relationships, so "insecure attachments" in childhood lead to problematic relationships in adulthood (Hazan \& Shaver 1987; Shaver \& Hazan, 1988). Similarly, early developmental feelings of economic security or insecurity may form the basis for lifelong mental models of person-object relations. In the particular instance examined here, felt formative insecurity becomes the blueprint for adult personality materialism. However, future research may wish to explore how more secure formative economic environments also serve as blueprints for adult person-object relations.

Finding the causes of materialism is a pressing concern, as is further exploration of the precise nature of the relation between materialism and negative outcomes for materialists. This article has made some headway in these issues by linking the origins of materialism to formative experiences. In so doing, it has provided a new theoretical model of materialism and laid the ground work for further research.

\section{ACKNOWLEDGMENTS}

Both authors contributed equally to this work and are listed in alphabetical order.

\section{REFERENCES}

Abramson, Paul R., \& Inglehart, Ronald. (1995). Value change in global perspective. Ann Arbor: University of Michigan Press.

Abramson, Paul R., \& Inglehart, Ronald. (1996). Formative security, education, and postmaterialism: A response to Davis. Public Opinion Quarterly, 60, 450-455.

Ahuvia, Aaron C., \& Wong, Nancy. (1995, May). Materialism:

Origins and implications for personal well-being. Paper presented at the European Conference of the Association for Consumer Research, Odense University, Denmark.

Andrews, Frank M., \& Withey, Stephen B. (1976). Social indicators of well-being: American perceptions of life quality. New York: Plenurm.

Bachman, Jerald G. (1983). Premature affluence: Do high school students earn too much? Economic Outlook USA, 10, 64-67.

Bagozzi, Richard P., \& Heatherton, Todd F. (1994). A general approach to representing multifaceted personality constructs: Application to state self-esteem. Structural Equation Modeling, 1, 35-67.

Becherer, Richard C., \& Morgan, Fred. (1982). Informal group influence among situationally/dispositionally oriented consumers. Joumal of the Academy of Marketing Science, 10, 269-281.

Belk, Russell W. (1982). Worldly possessions: Issues and criticisms. Advances in Consumer Research, 10, 514-519.

Belk, Russell W. (1983). Three scales to measure constructs related to materialism: Reliability, validity and relationships to measures of happiness. In Thomas Kinnear (Ed.), Advances in Consumer Research, II, 291-97.

Belk, Russell W. (1985). Materialism: Trait aspects of living in the material world. Journal of Consumer Research, 12, 265-280.

Belk, Russell W., \& Ger, Guliz. (1995). Global and local meanings of materialism: A qualitative study across cultures. Manuscript in preparation.

Bengston, Verm L. (1975). Generation and family effects in value socialization. American Sociological Review, 40, 358-371.

Bourdieu, Pierre. (1984). Distinction: A social critique of the judgement of taste. Cambridge, MA: Harvand University Press.

Bowlby, J. (1973). Affectional bonds: Their nature and origin. In R. Wiess (Ed.), Loneliness: The experience of emotional and social isolation (pp. 38-52). Cambridge, MA: MIT Press

Corsaro, William A., \& Elder, Donna. (1990). Children's peer cultures. Annual Review of Sociology, 16, 197-220.

Elkin. Frederick, \& Handel, Gerald. (1988). The child and snciety. New York: Random House.

Fournier, Susan, \& Richins, Marsha L. (1991). Some theoretical and popular notions conceming materialism. Journal of Social Behavior and Personality, 6, 403-414.

Freedman, Deborah S., \& Thornton, Arland. (1990). The consumption aspirations of adolescents: Determinants and implications. Youth and Society, 21, 259-281.

Ger, Guliz, \& Belk, Russell W. (1996). Cross-cultural differences in materialism. Journal of Economic Psychology, 17, 55-77.

Greenberger, Ellen, \& Steinberg, Laurence. (1986). When teenagers work. New York: Basic Books.

Hazan, Cindy, \& Shaver, Phillip. (1987). Romantic love conceptualized as an attachment process. Journal of Personality and Social Psychology, $52,511-524$.

Hellevik, Ottar. (1993). Postmaterialism as a dimension of cultural change. Intermational Journal of Public Opinion Research, 5, 211-233.

Holt, Douglas B. (1998). Does cultural capital structure American consumption? Journal of Consumer Research, 25, 1-25.

Inglehart, Ronald. (1971). The silent revolution in Europe: Intergenerational change in post-industrial societies. American Political Science Review, 65, 991-1017.

Inglehart, Ronald. (1977). The silent revolution: Changing values and political styles among Westem publics. Princeton, NJ: Princeton University Press. 
Inglehart, Ronald. (1979). Value priorities and socioeconomic change. In Samucl Barnes \& Max Kaase (Ed.), Political action: Mass participation in five Westem democracies (pp. 305-342). Thousand Oaks, CA: Sage.

Inglehart, Ronald. (1990). Culture shift in advanced industrial society. Princeton, NJ: Princeton University Press.

Kasser, Tim. (2002). The high price of materialism. Boston: MIT Press.

Kasser, Tim, \& Ryan, Richard M. (1993). A dark side of the American dream: Correlates of financial success as a central life. Joumal of Personality and Social Psychology, 65, 410-422.

Kasser, Tim, Ryan, Richand M., Zax, Melvin, \& Sameroff, Amold J. (1995). The relations of matemal and social environments to late adolescents' materialistic and prosocial values. Developmental Psychology, 31. 907-914.

La Barbera, Prescilla A., \& Gurhan, Zeynep. (1997). The role of materialism, religiosity, and demographics in subjective well-being. Psychology and Marketing. 14, 71-97.

Larsen, Randy J., \& Diener, Edward. (1987). Affect intensity as an individual difference characteristic: A review. Joumal of Research in Personality. 2I, 1-39.

Larsen, Val, Sirgy, Joseph M., \& Wright, Newell D. (1999). Materialism: The construct, measures, antecedents, and consequences. Academy of Marketing Studies Joumal, 3, 75-107.

Lesthaeghe, Ron, \& Meekers, Dominique. (1986). Value changes and the dimensions of familism in the European community. European Joumal of Population, 2, 225-268.

Magnusson. David. (1990). Personality development from an interactional perspective. In Lawrence A. Pervin (Ed.), Handbook of personality: Theory and research (pp. 193-222). New York: Guilford.

Marsh, Alan. (1975). The silent revolution, value priorities and the quality of life in Britain. American Political Science Review, 69, 21-30.

Marsh, Herbert W., Balla, John R., \& Hau, Kit-T. (1996), An evaluation of incremental fit indices: A clarification of mathematical and empirical properties. In George A. Marcoulides \& Randall E. Schumacker (Eds.), Advanced structural equation modeling: Issues and Techniques (pp. 315-353). Mahwah, NJ: Lawrence Erlbaum Associates, Inc.

Mastow, Abraham H. (1970). Motivation and persnnality. New Yox: Harper \& Row.

Mick, David Glen. (1996). Are studies of dark side variables confounded by socially desirable responding? The case of material ism. Joumal of Consumer Research, 23, 106-119.

Moore, Roy L., \& Moschis, George P. (1981). The effects of family communication and mass media use on adolescent consumer learning. Joumal of Communication, 3/(1), 42-51.

Moschis, George P. (1976). Social comparison and informal group influence. Joumal of Marketing Research, 13, 237-244.

Moschis, George P. (1978). Acquisition of the consumer role by adolescents. Atlanta, GA: Georgia State University, College of Business Administration, Publishing Services Division.

Moschis, George P. (1987). Consumer socialization: A life-cycle perspective. Lexington, MA: Lexington.

Moschis, George P., \& Moore, Roy L. (1979). Family communication and consumer socialization. In William L. Wilkie (Ed.), Advances in consumer research, 6, 359-363. Ann Arbor, MI: Association for Consumer Research.

Mueller, Daniel J., \& Womhoff, Steven A. (1990). Distinguishing personal and social values. Educational and Psychological Measurement, 50, 691-699.

Nunnally, J.C. (1978). Psychometric theory. New York: McGraw-Hill
O'Guinn. Thomas C., \& Shrum, L. J. (1997). The role of television in the construction of consumer reality. Joumal of Consumer Research, 23. 278-294.

Pollay, Richard W. (1987). On the value of reflections on the values in "the distorted mirror." Joumal of Marketing, 51, 104-109.

Preston, Samuel H. (1986). Changing values and falling birth rates. Population and Development Review, 12, 176-200.

Princen, Thomas. (1997). The shading and distancing of commerce: When intemalization is not enough. Ecological Economics, 20, 235-253.

Richins, Marsha L. (1987). Media, materialism, and human happiness. In $M$ Wallendorf and P. Anderson (Eds.), Advances in consumer research, 14, 352-356. Provo, UT: Association for Consumer Research.

Richins, Marsha L. (1994a). Special possessions and the expression of material values. Joumal of Consumer Research, 21, 522-533.

Richins, Marsha L. (1994b). Valuing things: The public and private meanings of possessions. Joumal of Consumer Research, 21, 504-521.

Richins, Marsha L. (1996). Materialism, desire, and discontent: Contributions of idealized advertising images and social comparison. In Ronald P. Hill (Ed.), Marketing and consumer research in the public interest (pp. 109-132). Thousand Oaks, CA: Sage.

Richins, Marsha L., \& Dawson, Scott. (1992). A consumer values orientation for materialism and its measurement: Scale development and validation. Journal of Consumer Research, 19, 303-316.

Richins, Marsha L., \& Rudmin, Floyd W. (1994). Materialism and Economic Psychology. Journal of Economic Psychology, 15, 217-231.

Rindfleisch, Aric, Burroughs, James E., \& Denton. Frank. (1997). Family structure, materialism, and compulsive consumption. Joumal of Consumer Research, 23, 312-325.

Shaver, Phillip R., \& Hazan, Cindy (1988). A biased overview of the study of love. Joumal of Social and Personal Relationships, 5, 473-501.

Sirgy, Joseph M. (1997). Materialism and quality of life. Social Indicators Research, 6, 1-34.

Sirgy, Joseph M., Lee, Dong-Jin, Kosenko, Rustan, Meadow, H. Lee, Rahtz, Don, Cicic, Muris, et al. (1998). Does television viewership play a role in the perception of quality of life? Journal of Advertising, 27, 125-142.

Sirgy, Joseph M., Lee, Dong-Jin, Larsen, Val, \& Wright, Newell. (1998) Satisfaction with material possessions and general well-being: The role of materialism. Joumal of Consumer Satisfaction, Dissatisfaction, and Complaining Behavior, 11, 103-118.

Sornentino, Richard M. \& Higgins, E. Tory. (1986). Motivation and cognition: Warming up to synergism. Richard M. Sorrentino \& E. Tory Higgins (Eds.), Handbook of motivation and cognition (pp. 3-19). New York: Wiley.

Thomton, Arland. (1989). Reciprocal influences of family and religion in a changing world. Jourmal of Marriage and the Family, 47, 381-394.

Ward, Scott, \& Wackman, Daniel. (1971). Family and media influences on adolescent consumer learning. American Behavioral Scientist. 14(4), 415-427.

Wright, Newell D., \& Larsen, Val. (1993). Materialism and life satisfaction A meta-analysis. Joumal of Consumer Satisfaction. Dissatisfaction. and Complaining Behavior, 6, 158-165.

Wu, Ping. (1998). Goal structures of materialists vs. non-materialists: The effects of TV exposure on materialism and the relationship between meterialism and happiness. Unpublished doctoral dissertation, Communications Department, University of Michigan, Ann Abor.

Accepted by Curt Haugtvedt. 